Revista Brasileira de Farmacognosia Brazilian Journal of Pharmacognosy 22(6): 1338-1343, Nov./Dec. 2012

Article

Received 15 Jun 2012

Accepted 13 Sep 2012

Available online 11 Oct 2012

Keywords:

Acacia leucophloea

wound healing

skin ointment

biochemical

histopathological

ISSN 0102-695X

http://dx.doi.org/10.1590/S0102-

695X2012005000121

\section{Evaluation of wound healing activity of Acacia leucophloea bark in rats}

\author{
Sembian Suriyamoorthy, Kalidass Subramaniam," Femina \\ Wahab, Karthikeyan $G$
}

Department of Biotechnology, School of Biotechnology and Health Sciences, Karunya University, Tamil Nadu, India.

\begin{abstract}
Wound healing activity of the bark extracts of Acacia leucophloea Willd., Fabaceae, was investigated by excision and incision wound healing models in Wistar male rats. Ethanolic extract based ointment of A. leucophloea bark (2 and 5\% (w/w)) was formulated and evaluated for its wound healing in Wistar male rats. In comparision with a standard wound healing ointment betadine. A. leucophloea ethanolic extract ointment exhibited marked wound healing activity and significantly enhanced the wound contraction and the period of epithelialization as assessed by wound contraction rate, tensile strength, increasing of DNA, collagen and protein synthesis and histopathological examination. The formulated ointment might well find use as skin repair agent without hazard to human health based on these results.
\end{abstract}

\section{Introduction}

Pathogens causing wound infections like Staphylococcus aureus, Streptococcus pyogens, Escherichia coli, Klebsiella pneumonia, Pseudomonas aeruginosa and Streptococcus pneumonia developed resistance against the targeted antibiotics. Such antibiotics were also proved to have adverse effects to humans (Mertz \& Ovigton, 1993). Hence, extraction of biologically active compounds from plant species is necessary (Essawi \& Srour, 2000). Therapeutic activity of a plant for a particular disease can be assessed by their chemotaxonomic examination or ethanobotonical information (Juneja et al., 2007).

Wound is simply a loss of cellular and functional continuity of living tissue. Although the process of wound healing is natural, an infection can delay healing (Subramoniam et al., 2001). Traditional use of plants for wound healing was because of their fibroblast growth stimulation and antioxidant effects (Houghton et al., 2005). The four phases of wound healing (Puratchikody etal., 2006) requires collaborative efforts of different tissues. This involves blood clotting and platelet aggregation, inflammatory response to injury, fibrin formation, altered ground substances, re-epithelialization and angiogenesis. Healing will be complete only after the disrupted surface was firmly knit by collagen (Govindarajan et al., 2007).

Free radical scavenging enzymes (FRSE) can deactivate and remove reactive oxygen species
(ROS) which are deleterious to wound healing due to their harmful effects on tissue (Aliyeva et al., 2004) protection of tissues from oxidative damage and thereby increasing wound healing percentage can be done by topically applying the compounds with free radical scavenging properties.

Acacia leucophloea (reonja) a moderate sized tree (20 to $30 \mathrm{ft}$ and a girth of 2 to $3 \mathrm{ft}$ ) (Kaul, 1963), belongs to the family Fabaceae. Its largest continuous distribution is arid India through Sri Lanka, Bangladesh, Burma and much of Thailand (Nielsen, 1992). Traditionally the bark is used as astringent, demulcent, constipating, expectorant and antipyretic, vulnerary, demulcent, bitter, thermogenic, styptic, alexeteric, antihelmintic, vulnerary, constipating, bronchitis, cough, diarrhoea, dysentery, vomiting, wounds, ulcers, internal and external haemorrhages, dental caries, oral ulcers, proctoptosis, stomatitis and intermittent fevers.

Survey of published literatures revealed the presence of secondary metabolites (steroids, alkaloids, carbohydrates, flavonoids, tannins, glycosides, polyphenols, gums and mucilage), antimicrobial and antioxidant activity of $A$. leucophloea ethanolic extract (Anjaneyulu et al., 2010).In spite of these records, wound healing property of A. leucophloea has not been evaluated. Keeping this in view, the present study was carried out to evaluate the folkloric information on wound healing activity of Acacia leucophloea. 


\section{Materials and Methods}

\section{Plant material collection and extraction}

Fresh barks of Acacia leucophloea Willd., Fabaceae, were collected from Sulur, Coimbatore district, Tamil nadu, India. Authentication of the plant was done by Botanical Survey of India Southern Regional Centre, TNAU campus, Coimbatore, Tamil nadu, India. (No.BSI/SRC/5/23/2012-13/Tech-460). The barks were air-dried, pulverized to a coarse powder in a mechanical grinder, passed through a 40 mesh sieve. Powder $(25 \mathrm{~g})$ were extracted with 250 $\mathrm{mL}$ of ethanol in Soxhlet extractor. The extract was decanted filtered with Whatman no.1 filter paper and concentrated at reduced pressure below $40^{\circ} \mathrm{C}$ through rotavapour to obtain cream of extract. The Acacia leucophloea ethanolic extract (ALEE) were stored in a closed container until further evaluation of wound healing activity.

\section{Preparation of formulation and standard used}

Two types of formulations with different concentrations 2 and 5\% (w/w) of ALEE were prepared by tituration method in a ceramic morter and pestle (Cooper \& Guns, 1987). Reference Standard (betadine ointment) was compared with the formulations to check the wound healing potential in different animal models.

\section{Animals}

Wistar male rats weighing approximately 150 $175 \mathrm{~g}$ were used in the study. The rats were acclimatized to the laboratory environment for a period of seven days. The rats were housed at $24 \pm 2{ }^{\circ} \mathrm{C}$ at a relative humidity of $40-45 \%$ and light dark cycles of 11 and $13 \mathrm{~h}$, respectively. Animals were provided with rodent diet and water ad libitum. The animal study protocol was subjected to the scrutiny of Institutional Ethical Committee and was cleared by same before beginning the experiment (IAEC/KU/BT /12/010).

\section{Acute dermal toxicity}

Acute dermal toxicity study was carried out to determine the dose as per OECD guidelines No. 402 (OECD guidelines, 1987). ALEE ointment with highest concentration $(5 \% \mathrm{w} / \mathrm{w})$ was applied on the shaved dorsal region of the rats.

\section{Grouping of animals}

Two wound models were used in our study: i) excision wound model and ii) incision wound model, containing four groups each. The groups were:

Group 1: Control (treated with Simple ointment base $(\mathrm{SOB}))(\mathrm{n}=6)$

Group 2: Standard group treated with betadine ointment $(n=6)$

Group 3: Treated with 2\% ALEE ointment $(n=6)$

Group 4: Treated with 5\% ALEE ointment $(n=6)$

\section{Excision wound model}

The animals in each group were anaesthetized by the open mask method with anaesthetic ether. Depilation's of the rats were done on the dorsal side. The excision wound was inflicted by cutting away a $100 \mathrm{~mm}^{2}$ full thickness of skin from predetermined shaved area (Saha et al., 1997). Excision wound was left undressed. Topical application of the drugs to the divided group's viz. SOB, Reference Standard (betadine ointment), ALEE $2 \% \mathrm{w} / \mathrm{w}$ ointment and ALEE $5 \% \mathrm{w} / \mathrm{w}$ ointment, respectively, were done until the wound heals completely. Wound contraction and epithelialization period was monitored. Biochemical parameters were done to estimate total protein, DNA, hexosamine, total collagen and uronic acid in the granulation tissues of control and experimental wounds. Histopathological analysis of the tissue from the healed wound was also done (Taranalli et al., 2004).

\section{Incision wound model}

The animals in each group were anaesthetized and one paravertebral long incision of $4 \mathrm{~cm}$ length on the depilated dorsal side was made through the skin till the cutaneous muscle. Aseptic measures were not taken throughout the experiment (Udupa et al., 1995). After incision was made the parted skin was kept together and stitched with black silk surgical thread (No.000) at $1 \mathrm{~cm}$ intervals using curved needle (No. 11). Good closure of the wound was made by tightening the edges of the thread and was left undressed. ALEE ointments along with SOB and reference standard were applied topically to their respective groups. The sutures were removed on $9^{\text {th }}$ day. Tensile strength of the cured skin was measured using tenisiometer (Hemalatha et al., 2001).

\section{Parameters evaluated for wound healing}

\section{Measurement of wound contraction}

The periphery of the excision wound was traced on a transparent paper on every $3^{\text {rd }}$ day, till the wound gets healed. Wound area was measured by retracing the wound on a millimeter scale graph paper (Sadaf 
et al., 2006). The evaluated surface area was used to calculate the percentage of wound contraction (Sadaf et al., 2006).

$\%$ of wound contraction $=\frac{\text { Initial would size }- \text { Specific day wound size }}{\text { Initial wound size }} \times 100$

\section{Epithelialization period}

The wound was monitored for complete epithelialization. It was measured in days from wounding day (day zero) till the Escher totally separated itself with the raw wound left behind.

Tensile strength of incision wound model

The degree of wound healing is directly proportional to the gain in tensile strength of the tissue. Tensile strength was measured on $10^{\text {th }}$ day. The tensile strength of ALEE ointment treated wounds was compared with control and reference standard treated groups.

\section{Biochemical estimations}

Protein was estimated by the method of Lowry et al. (1951). As per Burton (1956) estimation of DNA was done. An uronic acid level was estimated by the method of Schiller et al. (1961). Hexosamine and collagen was estimated by the method of Woessner, (1979).

\section{Histopathological examination}

The cross sectional full thickness skin specimens from each group were collected at the end of the experiment to evaluate for the histopathological analysis. Samples were fixed in 5\% buffered formalin, processed and blocked with paraffin and then sectioned into $5 \mu \mathrm{m}$ sections and stained with hematoxylin and eosin (HE) stains. The tissues were examined by light microscope for epidermal remodeling.

\section{Statistical analysis}

Results obtained from three wound models have been expressed as mean \pm SEM. The data was evaluated by one way ANOVA followed by Dunnett's T-Test, $p<0.05$ and $p<0.01$ was considered as significant.

\section{Results}

\section{Wound contraction studies}

Reduction of wound area of different groups on $16^{\text {th }}$ day for excision wound model (Table 1) was recorded. Control groups showed least rate of wound healing. Reference standard heals the wound almost equivalent to the groups treated with $2 \%$ (w/w) ALEE ointment. Faster rate of wound healing was seen in groups treated with 5\% (w/w) ALEE ointment.

\section{Epithelialization period}

The epithelialization was observed from the first day. The epithelialization time was found to be lesser for group IV. Epithelialization was quicker in group treated with ALEE $5 \%(w / w)$ ointment than the ALEE $2 \%(\mathrm{w} / \mathrm{w})$ ointment and Reference standard treated groups (Table 1 ).

\section{Measurement of tensile strength}

Table 2 compares the tensile strength of the healed skin of different groups. Minimum tensile strength was noticed in untreated group. Among the tensile strength of the tissues treated with other ointments; ALEE 5\% (w/w) ointment was highest. Reference standard and ALEE 2\%(w/w) exerts more or less same results. This confirms that extract of Acacia leucophloea bark possesses excellent wound healing property by seeing the tensile strength.

Table 1. Effect of creams prepared 2 and 5\% w/w of Acacia leucophloea bark ethanolic extract on excision wound model $($ mean $\pm \mathrm{SD})$.

\begin{tabular}{|c|c|c|c|c|c|}
\hline \multirow{2}{*}{ Group } & $4^{\text {th }}$ day & $8^{\text {th }}$ day & $12^{\text {th }}$ day & $16^{\text {th }}$ day & \multirow{2}{*}{$\begin{array}{c}\text { Period of } \\
\text { epithelialization in } \\
\text { days }\end{array}$} \\
\hline & $\%$ Area closure & $\%$ Area closure & $\%$ Area closure & $\%$ Area closure & \\
\hline Control & $32.35 \pm 1.34$ & $62.33 \pm 2.05$ & $65.56 \pm 1.75$ & $83.08 \pm 1.41$ & 21.56 \\
\hline Betadine & $34.8 \pm 0.98 *$ & $64.1 \pm 0.87 * *$ & $86.6 \pm 1.82 * *$ & $96.9 \pm 1.56 * *$ & 17.67 \\
\hline ALEE $2 \%$ & $54.4 \pm 1.63 * *$ & $69.6 \pm 1.53 *$ & $91.33 \pm 1.78^{*}$ & $96.9 \pm 1.21 * *$ & 17.67 \\
\hline ALEE 5\% & $58.9 \pm 1.21 *$ & $71.6 \pm 1.46^{* *}$ & $93.16 \pm 1.91 * *$ & $98.1 \pm 1.83 *$ & 16.40 \\
\hline
\end{tabular}

$* p<0.05 ; * * p<0.01$. 
Table 2. Effect of creams prepared 2 and 5\% w/w of Acacia leucophloea bark ethanolic extract on incision wound model.

\begin{tabular}{ccc}
\hline S.No. & Groups & Tensile strength $(\mathrm{g})($ mean \pm SD) \\
\hline 1 & Control & $347.24 \pm 1.71$ \\
2 & Betadine & $653.89 \pm 0.52^{*}$ \\
3 & ALEE $2 \%$ & $694.32 \pm 1.34 *$ \\
4 & ALEE $5 \%$ & $783.91 \pm 1.02 * *$ \\
\hline
\end{tabular}

\section{Biochemical estimations}

Table 3 depicts the total protein, DNA, hexosamine, total collagen and uronic acid in the granulation tissues of control and experimental wounds. ALEE treatment significantly increases the DNA content from day 4 to day 12. A similar trend was observed in the treated groups, with a significant increase in the collagen content. Hexosamine and uronic acid gradually increased till day 8 .

\section{Histopathological examination}

Histopathological examination (Figure 1) of the tissue treated with ALEE ointments have led to reduce scar formation and exhibits enhanced fibroblast proliferation, angiogenesis, keratinisation and epithelialization as compared to reference standard and control groups.

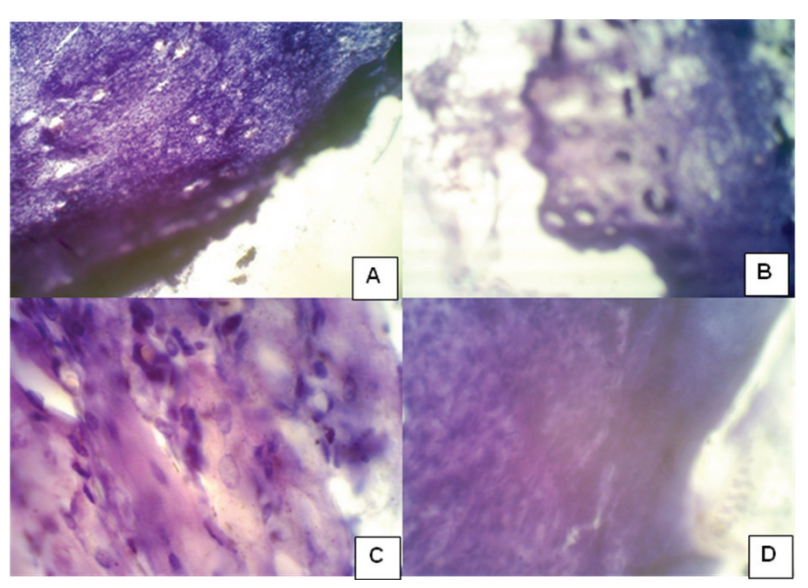

Figure 1. Sections stained with haematoxylin-eosin (x40) A. Wound histology of control rat; B. Wound histology of rat treated with Std. betadine; C. Wound histology of rat treated with creams prepared 2\% w/w of Acacia leucophloea bark ethanolic extract; D. Wound histology of rat treated with creams prepared 5\% w/w of Acacia leucophloea bark ethanolic extract on excision wound model.

\section{Discussion and Conclusion}

The plant Acacia leucophloea Willd., Fabaceae, is reported to have great medicinal value in Indian medicine. A. leucophloea is used extensively in

Table 3. Biochemical parameters (mean $\pm \mathrm{SD}$ ) of Acacia leucophloea bark ethanolic extract on excision wound model.

\begin{tabular}{|c|c|c|c|c|c|}
\hline Biochemical parameters & Groups & $4^{\text {th }}$ day & $8^{\text {th }}$ day & $12^{\text {th }}$ day & $16^{\text {th }}$ day \\
\hline \multirow[t]{4}{*}{ Total protein (mg/100 mg wet tissue) } & Control & $2.67 \pm 1.32$ & $4.18 \pm 1.57$ & $6.79 \pm 1.43$ & $5.43 \pm 1.67$ \\
\hline & Betadine & $4.42 \pm 0.94 * *$ & $5.98 \pm 1.27 * *$ & $6.84 \pm 2.12 * *$ & $3.94 \pm 1.03 * *$ \\
\hline & ALEE $2 \%$ & $4.54 \pm 1.83^{*}$ & $6.17 \pm 1.54 * *$ & $6.92 \pm 0.83 *$ & $3.90 . \pm 1.48^{* *}$ \\
\hline & ALEE 5\% & $4.66 \pm 1.08 *$ & $6.49 \pm 1.79 * *$ & $7.91 \pm 1.61 * *$ & $3.89 \pm 1.34 * *$ \\
\hline \multirow[t]{4}{*}{ DNA (mg/100 mg wet tissue) } & Control & $1.78 \pm 1.46$ & $6.32 \pm 1.98$ & $4.12 \pm 1.37$ & $3.24 \pm 0.97$ \\
\hline & Betadine & $2.83 \pm 2.01 * *$ & $6.59 \pm 1.33 * *$ & $7.81 \pm 1.29 *$ & $2.86 \pm 1.63 * *$ \\
\hline & ALEE $2 \%$ & $2.98 \pm 1.00 *$ & $6.64 \pm 0.86^{*}$ & $7.96 \pm 1.73 * *$ & $2.59 \pm 1.58 *$ \\
\hline & ALEE 5\% & $3.08 \pm 1.21 * *$ & $6.84 \pm 1.48 * *$ & $8.01 \pm 1.01 *$ & $2.37 \pm 1.60 *$ \\
\hline \multirow[t]{4}{*}{ Hexosamine ( $\mu \mathrm{g} / 100 \mathrm{mg}$ dry tissue) } & Control & $698 \pm 1.15$ & $544 \pm 1.73$ & $392 \pm 1.18$ & $315 \pm 1.69$ \\
\hline & Betadine & $894 \pm 0.91 * *$ & $907 \pm 1.19 *$ & $937 \pm 0.87 * *$ & $293 \pm 1.08 * *$ \\
\hline & ALEE $2 \%$ & $924 \pm 1.46 * *$ & $908 \pm 1.55 * *$ & $951 \pm 2.05 *$ & $289 \pm 1.13 * *$ \\
\hline & ALEE $5 \%$ & $942 \pm 0.98 *$ & $912 \pm 1.19^{*}$ & $964 \pm 1.06 * *$ & $243 \pm 1.23 * *$ \\
\hline \multirow[t]{4}{*}{ Total collagen (mg/100 mg dry tissue) } & Control & $1.83 \pm 1.44$ & $3.81 \pm 1.82$ & $3.57 \pm 1.07$ & $3.37 \pm 0.89$ \\
\hline & Betadine & $2.91 \pm 1.70 *$ & $5.83 \pm 1.02 * *$ & $7.95 \pm 1.86^{*}$ & $2.86 \pm 1.11 * *$ \\
\hline & ALEE $2 \%$ & $3.23 \pm 0.90 * *$ & $5.87 \pm 1.78 *$ & $8.13 \pm 1.33^{*}$ & $2.71 \pm 1.29 * *$ \\
\hline & ALEE 5\% & $3.53 \pm 1.59 * *$ & $6.11 \pm 0.82 *$ & $8.20 \pm 1.14^{* *}$ & $2.59 \pm 1.00 *$ \\
\hline \multirow[t]{4}{*}{ Uronic acid ( $\mu \mathrm{g} / 100 \mathrm{mg}$ dry tissue) } & Control & $97 \pm 2.08$ & $89.30 \pm 1.38$ & $86 \pm 1.81$ & $83.87 \pm 1.90$ \\
\hline & Betadine & $94.32 \pm 1.39 * *$ & $103 \pm 1.14^{*}$ & $92.22 \pm 0.99 * *$ & $81 \pm 1.06^{* *}$ \\
\hline & ALEE $2 \%$ & $91 \pm 1.73 * *$ & $107.40 \pm 1.69 *$ & $96 \pm 1.54 * *$ & $80 \pm 1.92 * *$ \\
\hline & ALEE 5\% & $89.49 \pm 1.02 * *$ & $111 \pm 1.29 * *$ & $103.68 \pm 2.07^{*}$ & $79.54 \pm 1.37 * *$ \\
\hline
\end{tabular}

$* p<0.05 ; * * p<0.01$ 
the Traditional System of Medicine for the treatment of number of ailments (Gupta et al., 2010). Ignacimuthu et al. (2008) has reported that the ethno medicinal plant Acacia leucophloea has been used for wound healing by the paliyar tribes of Madurai district Tamilnadu, India.

There are no scientific reports on wound healing activity of this plant hence we have taken up this study with a view to identify the wound therapeutic potential of A. leucophloea. The wound healing study results manifest the potent wound healing of $A$. leucophloea ethanol extract (ALEE) as evident from the wound contraction, increased tensile strength and increased biochemical parameters in healing tissue, thus validate the ethnotherapeutic claim. Furthermore, the period of epithelialization was shorter in the treated wounds. Topical application of ALEE are effective in faster wound contraction due to the larger availability at the wound site, its angiogenic and mitogenic potential. Its prohealing activity was significantly increased as all the parameters observed were significantly enhanced.

In excision wound model, 5\% ALEE showed faster wound contraction compared with 2\% ALEE, reference standard and control groups (98.1 $\pm 1.83,96.9 \pm 1.21$, $96.9 \pm 1.56$ and $83.08 \pm 1.41$, respectively). In incision wound the increase in tensile strength of treated wounds (5 and $2 \%$ ALEE -783.91 \pm 1.02 and $694.32 \pm 1.34$ ) may be due to the increase in collagen concentration and stabilization of the fibres (Udupa et al., 1995). The stimulus of interleukin-8, an inflammatory a-chemokine which affects the function and recruitment of various inflammatory cells, fibroblasts and keratinocytes may be responsible for the acceleration of the wound contraction rate of ALEE. In the fibroblasts the gap junctional intercellular communication may be increased to induce a more rapid maturation of granulation tissues (Moyer et al., 2002).

The higher levels of steroids, polyphenols, tannins, alkaloids, gums and mucilage noted in the bark extracts of A. leucophloea could be responsible for the medicinal properties of this plant. Secondary metabolites that serve as the defensive agents and that are produced under stressed condition by the plants provide invaluable resources. Secondary metabolites have been used to find new drug molecules have historically served as templates for the development of many important classes of drugs (Fakim, 2006).

The wound healing action of ALEE may be probably due to the synergistic or individual activity of the phytoconstituents present in the plant. Literature reports on plant extracts have shown that phytochemical constituents like flavonoids (Tsuchiya et al., 1996), triterpenoids (Scortichini et al., 1991) and tannins (Rane et al., 2003) are known to enhance the wound healing process.

The biochemical evaluation of the wound animal model revealed the amplified DNA content in the treated wounds, which indicates cellular hyperplasia. Similarly there is an increase in the total protein content representing the active synthesis and deposition of matrix proteins in the granulation tissues. Estimation of collagen content in granulation tissues of control and experimental wounds clearly suggests that ALEE enhances collagen synthesis and deposition. The amount of collagen may be increased in total cell number as a result of increased cell division. The wound healing process is mainly accelerated by the regulated biosynthesis and deposition of new collagens and their subsequent maturation (Dunphy \& Udupa, 1956a). The synthesis of new extracellular matrix is improved by the matrix molecules hexosamine and uronic acid which acts as a ground substratum.

In ALEE treated wounds the levels of hexosamine and uronic acid increased until day 8 post wounding and decreased thereafter. Similar trend was reported earlier that there is an increase in the levels of these components during the early stages of wound healing, following which normal levels are restored (Dunphy \& Udupa, 1956b). Wound healing differs pathologically making it complex to discuss the results obtained with one type of wound model. ALEE when topically applied on rats showed convincing wound healing suggesting that it enhances various stages of healing process. Ethnopharmacologically the bark of $A$. leucophloea has significant prohealing activity.

It is also reported that the A. leucophloea has wonderful antimicrobial activity (Anjaneyulu et al., 2010). The composition and concentration of secondary metabolites determines the antimicrobial efficiency of plants, hence it is also vivid from the literature that $A$. leucophloea can be used to control and cure wounds infected with microbes, nosocomial infections like bed sores and control multidrug resistant strains like Pseudomonas aeroginosa and Staphylococcus aureus. Previous findings have authenticated the usage of $A$. leucophloea by local people for treating skin diseases and against some bacterial and fungal infections (Anjaneyulu et al., 2010). Hence our laboratory involved in the studies that provide the basis for further isolation and evaluation of major active principles present in the plant material and test their efficiency against various multidrug resistant microbial strains like Methicillin Resistant Staphylococcus aureus (MRSA) and Acinetobacter baumannii. Further studies with purified phytoconstituents of Acacia leucophloea ethanol extract are in progress to comprehend the complete mechanism of wound healing activity.

\section{References}

Aliyeva E, Umur S, Zafer E, Acigoz G 2004. The effect of polylactide membranes on the levels of reactive oxygen species in periodontal flaps during wound healing. Biomaterials 25: 4633-4637.

Anjaneyulu E, Ramgopal M, Hemalatha S, Balaji M 2010. 
Phytochemical analysis, antimicrobial and antioxidant activity of the bark extracts of the bark extracts of Acacia leucophloea L. Global J Biotechnol Biochem 5: 231-236.

Burton K 1956. A study of the conditions and mechanism of the diphenylamine reaction for the colorimetric estimation of deoxyribonucleic acid. Biochem J 62: 315-323.

Cooper JL, Gunns C 1987. Dispensing for pharmaceutical students, $12^{\text {th }}$ ed. In: Carter SL (Ed.), CBS Publisher and Distributors, Delhi, p. 199-200.

Dunphy JE, Udupa KN 1956a. Chemical and histochemical sequences in the normal healing of wounds. New Engl $J$ Med 253: 847-852.

Dunphy JE, Udupa KN 1956b. Wound healing. A new perspective with particular reference to ascorbic acid deficiency. Ann Surg 144: 304-316.

Essawi T, Srour M 2000. Screening of some Palestinian medicinal plants for antibacterial activity. $J$ Ethnopharmacol 70: 343349.

Fakim AG 2006. Medicinal plants: Tradition of yesterday and drugs of tomorrow. Mol Aspects Med 27: 1-93

Govindarajan R, Kumar B, Vijaykumar M, Pushpangadan P 2007. Ethanopharmacological approaches to wound healing exploring medicinal plants of India. $J$ Ethnopharmacol 114: 103-113.

Gupta R, Gupta AK, Aiswarya G 2010. Pharmacognostical investigation on Acacia leucophloea leaf. Res J Pharm Biol Chem Sci 1: 360-365.

Hemalatha S, Subramanian N, Ravichandran V, Chinnaswamy $\mathrm{K}$ 2001. Wound healing activity of Indigofera ennaphylla Linn. Indian J Pharm Sci 63: 331-333.

Houghton PJ, Hylands PJ, Mensah AY, Hensel A, Deters AM 2005. In vitro tests and ethnopharmacological investigations; wound healing as an example. $J$ Ethnopharmacol 100: 100-107.

Ignacimuthu S, Ayyanar M, Sankarasivaraman K 2008. Ethnobotanical studyof medicinal plants used by paliyar tribals in theni district of Tamilnadu, India. Fitoterapia 79: 562-568.

Juneja JD, Shrivastava PN, Guha MK, Saxena RC 2007. Preliminary phytochemical screening of some folklore medicinal plants for their anti-inflammatory activity. Pharmacogn Mag 11: 201-203.

Kaul RN 1963. Need for afforestation in the acrid zone of India: Layaaran, vol.13.

Lowry OH, Rosebrough NJ, Farr Al, Randall RT 1951. Protein measurement with the folin phenol reagent. $J$ Biol Chem 193: 265-276.

Mertz PM, Ovington LG 1993. Wound healing microbiology. Dermatol Clin 11: 739-747.

Moyer KE, Saggers GC, Ehrlich HP 2002. Effects of interleukin-8 on granulation tissue maturation. J Cell Physiol 193: 173-179.
Nielsen IC 1992. Flora Malesiana: Mimosaceae. vol.1, 45 p.

OECD 1987. Guidelines for the Testing of Chemicals/Section 4: Health Effects:Acute Dermal Toxicity Test No. 402.

Puratchikody A, Nithya C, Nagalakshmi G 2006. Wound healing activity of Cyperus rotundus Linn. Indian $J$ Pharm Sci 68: 97-101.

Rane M, Madhura, Mengi A, Shusma 2003. Comparative effect of oral administration and topical application of alcoholic extract of Terminalia arjuna bark on incision and excision wounds in rats. Fitoterapia 74: 553-558.

Sadaf F, Saleem R, Ahmed M, Ahmed SI, Navaid-ul-zafer 2006. Healing potential of cream containing extract of Sphaeranthus indicus on dermal wounds in guinea pigs. J Ethnopharmacol 107: 161-163.

Saha K, Mukherjee PK, Das J, Pal M, Saha BP 1997. Wound healing activity of Leucas lavandulaefolia Rees. $J$ Ethnopharmacol 56: 139-144.

Schiller S, Slover G, Dorfman AA 1961. A new perspective with particular reference to ascorbic acid deficiency. J Biol Chem 36: 983-985.

Scortichini M, Pia, Roosi MJ 1991. Preliminary in vitro evaluation of the antimicrobial activity of terpenes and terpenoids towards Erwinia amylovora. Appl Bacterioly 71: 109-112.

Subramoniam A, Evans DA, Rajasekharan S, Nair GS 2001. Effect of Hemigraphis colorata (Blume) H. G. Hallier leaf on wound healing and inflammation in mice. Indian J Pharmacol 33: 283-285.

Taranalli AD, Tipare SV, Kumar S, Torgal SS 2004.Wound healing activity of Oxalis corniculata whole plant extract in rats. Indian J Pharm Sci 66: 444-446.

Tsuchiya H, Sato M, Miyazaki T, Fujiwara S, Tanigaki S, Ohyama M, Tanaka T, Linuma M 1996. Comparative study on the antibacterial activity of phytochemical flavanones against methicillin resistant Staphylococcus aureus. J Ethnopharmacol 50: 27-34.

Udupa D, Kulkarni R, Udupa SL 1995. Effect of Tridax procumbens extracts on wound healing. Int J Pharmacol 33: $37-40$.

Woessner JR 1979. The determination of hydroxyl proline in tissue and protein samples containing small proportions of this imino acid. Arch Biochem Biophys 93: 440-447.

\section{*Correspondence}

\section{Kalidass Subramaniam}

Department of Biotechnology, School of Biotechnology and Health Sciences, Karunya University, Karunya Nagar, Coimbatore, 641114, Tamil Nadu, India

kalidass@karunya.edu

Tel.: 914222614300 Ext. 4499

Fax: 91 422-2615615 